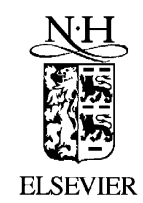

\title{
Resources, real options, and corporate strategy is
}

\author{
Antonio E. Bernardo*, Bhagwan Chowdhry
}

The Anderson School at UCLA, Los Angeles, CA 90095-1481, USA

Received 22 May 2000; received in revised form 23 May 2001

\begin{abstract}
The types of investments a firm undertakes will depend in part on what it expects the outcome of those investments to reveal about its skills, capabilities, and assets (i.e., its resources). We predict that a firm will specialize when young, then experiment in a new line of business for some time, and then either expand into a large, multisegment business or focus and scale up its specialized business. We derive several empirical implications for firm valuations and the reaction of stock prices to news about firm prospects. We also offer a novel explanation for the well-documented "diversification" discount. (C) 2002 Published by Elsevier Science B.V.
\end{abstract}

JEL classification: D83; G30; G31

Keywords: Real options; Valuation; Corporate strategy; Resources; Learning

\section{Introduction}

A firm's investment strategy is determined by leveraging the capabilities, skills, and assets (i.e., resources) that are the source of its competitive advantage (Penrose, 1959; Wernerfelt, 1984). However, a firm might be uncertain about the degree to which its resources will generate economic rents. One way that firms learn about

\footnotetext{
${ }^{27}$ We thank Michael Brennan, Matthias Kahl, Steve Lippman, Steve Postrel, Richard Rumelt, Eduardo Schwartz, Avanidhar Subrahmanyam, Lenos Trigeorgis, Karen Van Nuys, David Wessels, and seminar participants at the Real Options Conference at Northwestern University, the AFA meetings in New York, the Texas Finance Conference, University of Arizona, London Business School, University of Michigan, Oxford University, and the University of Texas at Dallas for many useful comments. In particular, we thank Glenn MacDonald (the referee) whose numerous insightful comments and suggestions greatly improved the paper.

*Corresponding author. Tel.: + 1-310-825-2198; fax: + 1-310-206-5455.

E-mail address: abernard@anderson.ucla.edu (A.E. Bernardo).
} 
their resources is by undertaking investments and observing their outcomes (Jovanovic, 1982). The realizations of various performance measures, such as cash flows, revenues, and growth in market share, provide signals about the level of the firm's resources relevant for the success of their investments. These signals are valuable for guiding future investment decisions. Thus, when making investment decisions, firms will optimally consider both the stand-alone cash flows and the value of the information they expect to learn (Easley and Keifer, 1988).

Resources can be of many types and can also differ in their degree of specificity (Montgomery and Wernerfelt, 1988). For example, R\&D expertise might be valuable in only a small number of businesses, while more general resources, such as an efficient distribution system, can be leveraged in many different businesses. ${ }^{1}$ It can thus be important and useful for firms to experiment with new lines of business to help disentangle whether specific resources or general resources are responsible for their success. Such experimentation allows firms to focus on those (current and future) investments and business opportunities that best exploit their resources.

In Section 2, we develop a simple, discrete-state, discrete-time model to formalize these ideas. We consider a risk-neutral firm that must choose among numerous investment opportunities (projects). The net cash flows from any project depend on the firm's general resources, applicable to all projects, as well as on the firm's specific resources pertaining only to that project. We assume that the firm can scale up its investment in any project at any time and that this scaled-up investment is irreversible. The key feature of our model is that while the firm is uncertain about its general and specific resources, it can learn about them by observing the outcomes of its investments.

We further suppose that the firm has prior beliefs that it has a valuable specific resource applicable to a particular project. If the firm undertakes this specialized project, it learns about the sum of its general and specific resources, but not about each component separately. If the firm undertakes multiple projects, however, it can obtain a better signal about its general resources. We predict that firms will follow a life cycle which begins with undertaking the specialized project, then experimenting with a new line of business to learn about its resources, then either expanding into a large, multisegment business or focusing and scaling up its specialized business. ${ }^{2} \mathrm{We}$ show that similar investment opportunities can be valued differently when firms differ in their resource base and current life-cycle stage (which impacts the value of learning). We also predict that firms can dramatically increase the level and intensity of investment in a specialized line of business after failing in an unrelated line of business.

\footnotetext{
${ }^{1}$ Montgomery and Hariharan (1991), for instance, document evidence that marketing assets are an important source of diversified expansion. Matsusaka (1998) also argues that diversification is a process by which corporations search for productive new uses of their organizational capabilities. The concept of organizational capabilities is described in Chandler (1990).

${ }^{2}$ There is some evidence that diversification, defined as having operations in many segments, is positively related to firm age; see Mueller (1972) and Montgomery (1994). Matsusaka (1998) studies a sample of 63 firms that were diversified in 1972 and finds that most of these firms were specialized ten years earlier and many refocused over the next ten years.
} 
In Section 3, we extend our model to continuous distributions and continuous time to derive a richer set of implications. For example, firms that can observe performance measures with less noise will learn about their resources faster, which allows them to improve future investment decisions. A reasonable proxy for the degree of noise about resources is the correlation across time of the firm's earnings or cash flows. Consequently, we predict that firms with more highly correlated earnings (cash flows) across time will have higher market valuations. Furthermore, we predict that young firms will be more valuable than older firms with the same expected level of resources because younger firms have more to learn about their resources and therefore have more valuable real options. This implication of our model could potentially explain the "diversification" discount - the well-documented empirical result that the market value of firms operating in several business segments appears to be less than the sum of the market values of single-segment firms operating in corresponding businesses (Lang and Stulz, 1994; Berger and Ofek, 1995). Finally, we also provide empirical implications for stock price reactions to news about firm prospects. For example, we show that the announcement effects of positive and negative earnings news on a firm's stock price are asymmetric and depend on the firm's resource base, future investment opportunities, and current life-cycle stage.

There is a considerable literature on the effects of learning by firms. Arrow (1962) is the seminal work on the economic implications of learning-by-doing. In Jovanovic and MacDonald (1994a), firms improve their knowhow both by producing new knowledge (innovation) and by learning from others (imitation). Numerous papers explore learning via experimentation. In one strand of this literature, firms learn about some aspect of their external environment (e.g., Prescott, 1972; Grossman et al., 1977; Zeira, 1987; Rob, 1991; Berk et al., 1999; Ryan and Lippman, 2000). Our work, however, is most closely related to the strand of literature in which experimentation allows the firm to learn about its own characteristics. The classic work in this area is Jovanovic (1982), in which a firm learns about its costs as it operates in the industry. As a low-cost firm learns of its advantage, it optimally scales up production. The dynamics of this learning process yield numerous interesting implications. For example, smaller firms are predicted to have higher and more variable growth rates because they learn more than larger, more mature firms. Moreover, entry and exit from an industry occurs as efficient firms grow and survive while inefficient firms decline and fail. Hopenhayn (1992) extends this analysis by introducing a concept of stationary equilibrium in a competitive industry to account for entry, exit, and heterogeneity in the size and growth rate of firms. Our work differs from Jovanovic's in two important respects. First, in our framework, firms experiment with new projects to learn to what degree their resources can be exploited in different lines of business. ${ }^{3}$ Second, we derive many novel implications for firm valuations, return volatilities, and the reaction of stock prices to news about firm prospects.

\footnotetext{
${ }^{3}$ Mitchell (2000) also exploits the idea that knowledge gained from one project is portable and can be used to some extent in the operation of other projects to develop a theory of the relation between the optimal scale and scope of the firm.
} 


\section{A discrete-state, discrete-time model}

We consider a firm with numerous investment opportunities (projects). The net cash flows from undertaking a particular project depend on the firm's skills and capabilities (i.e., resources) pertaining to this project. These resources can be classified into two broad categories. General resources, denoted $G$, affect the cash flows of all projects. Specific resources, denoted $S^{i}$, affect the cash flows of a specific project indexed by $i$. The net cash flow from any project $i$ depends on the sum of these resources, denoted $R^{i}=G+S^{i}$. The values of the general and specific resources for a particular project $i$ are fixed but their precise values are unknown to the managers and investors. The most important feature of our model is the assumption that the project's net cash flow is observed only if the project is implemented. Consequently, the firm can only learn about its resources by undertaking projects and observing their performance. For simplicity, we assume that if the project is undertaken its net cash flow is observed without noise (in Section 3, we relax this assumption).

The firm can also choose to scale up its investment in any project by a factor $K^{i}>1$ at any time. This scaled-up investment is assumed to be irreversible and generates net cash flows of $K^{i} R$ in perpetuity; therefore, if we let $r$ denote the discount rate, the net present value of the scaled-up investment at any date $t$ is $\left(K^{i} / r\right) \mathrm{E}_{t}\left[R^{i}\right]$ where $\mathrm{E}_{t}$ denotes the expected value at date $t$. Absent any positive information about either its general or specific resources, we make the natural assumption that the firm's prior belief is that projects are not positive-NPV. This assumption captures the idea that a randomly chosen firm in the economy will not enter any line of business unless it has reason to believe that it owns valuable resources not available to other firms.

We will now assume that the firm believes it has a valuable specific resource applicable to a particular project. Let $S$ denote the true level of the specific resource the firm has for this project. The net cash flow from undertaking this project will thus be given by $R^{S}=G+S$. We will assume that the firm does not know the true value of $S$ but has reason to believe that $\mathrm{E}_{0}[S]>\mathrm{E}_{0}\left[S^{i}\right] \equiv \bar{S}$. For simplicity, we assume that $\bar{S}=0$. Thus, the firm expects that it has more valuable specific resources applicable to this project than to a typical project in the economy. We assume that the levels of resources $G$ and $S$ are drawn from independent binomial distributions. In particular, $G$ and $S$ take on one of two values: $H$ (high) or $L$ (low), with $H>0>L$. Let $\operatorname{Pr}[S=H]=p$ and $\operatorname{Pr}[G=H]=q$, which is common knowledge to the firm and its investors. All agents are risk neutral.

If the specialized project is undertaken, the firm observes $R^{S}=G+S$ precisely, which thereby allows it to learn perfectly the sum of its general and specific resources (but not each component separately). Although the firm expects higher net cash flows from adopting the project for which it has more valuable specific skills, it might also wish to invest in other projects to disentangle the true values of its general and specific resources. For example, taking the project with net cash flows $R^{S}=G+S$ provides the firm with an imprecise signal about $G$. To improve its estimate of $G$, the firm might take another project with $R^{i}=G+S^{i}$. A more precise signal about $G$, 
however, would be obtained if the firm could take a project for which the contribution of the specific resource is most predictable. This can be achieved by undertaking many available projects each requiring different specific resources. We assume that it is feasible for the firm to undertake a project that involves taking a large collection of projects from those available in which the firm has no valuable specific skills. Formally, the net cash flow from taking $N$ arbitrary projects, each of size $1 / N$, will equal $(1 / N) \sum_{i=1}^{N}\left(G+S^{i}\right)$. As $N$ gets large, we obtain a general project with cash flow $R^{G}=G+\bar{S}$, where $\bar{S}$ is attained with certainty (by the Law of Large Numbers). Consequently, adopting the project with cash flow $R^{G}$ allows the firm to infer perfectly its general resources, $G$.

At each date $t=0,1,2$, the firm must choose to either (i) cease operations, (ii) take the specialized project and/or the general project, or (iii) make an irreversible investment either in scaling up the specialized project (which generates cash flow in perpetuity with a net present value at that time of $K^{S} \mathrm{E}_{t}\left[R^{S}\right] / r$ ) or in building a large, multisegment business (which generates cash flow in perpetuity with a net present value at that time of $K^{G} \mathrm{E}_{t}\left[R^{G}\right] / r$ ). After date $t=2$, either all uncertainty is resolved or no important decisions remain to be made by the firm.

Our model captures several interesting and intuitive features. First, we can choose the exogenous parameters $K^{S}$ and $K^{G}$ to be larger than one to represent the idea, endogenized in Mitchell (2000), that once the firm learns that its resources are valuable, it can build similar resources to some extent and scale up the business it finds profitable. However, such expansion is not trivial and perhaps requires the firm to commit resources at the expense of some flexibility in deploying its resources. This is captured by requiring that the expansion be an irreversible act. Second, we can capture the idea that general resources can be more valuable (because they can be used in many different businesses) by choosing the parameter $K^{G}$ to be much larger than the parameter $K^{S}$. For what follows we will assume that $K^{G} \geqslant 2 K^{S}$.

In our model, investments can enhance firm value in two ways: first, they can produce positive net cash flows, and second, they produce information about the firm's resources which can be used to make better investment decisions in the future. On average, the firm's estimate of its resources will be neither enhanced nor diminished by taking a project; however, the information will be valuable to the firm because the option to make the large, irreversible investment makes the value of positive new information greater than that of negative new information. Consequently, even if the project has a negative net present value on a stand-alone basis, it could still be optimal to invest in the project if the information value is sufficiently high. Similarly, the firm will not necessarily find it optimal to make the irreversible investment when the expected cash flows from the projects become positive.

\subsection{Solution}

Recall our assumptions that (i) absent any positive information, all projects are not positive-NPV and (ii) if the firm has both high general and high specific 
resources, it will choose to expand in the multisegment business (note that $K^{G} \geqslant 2 K^{S}$ is sufficient for this). Under these conditions, we have the following result.

Lemma 1. At date 0, the firm will not choose to undertake both the general project and the specialized project.

Proof. See the appendix.

The intuition for the proof is that simultaneously undertaking the general project and the specialized project is dominated by first taking only the specialized project and postponing the decision to undertake the general project for one period. This is because any advantage in learning $G$ is not exploited in deciding whether or not to undertake the specialized project when the firm simultaneously undertakes both projects. Since the net present value of taking only the general project is nonpositive, the result follows.

Lemma 1 implies that there are two interesting cases to consider, described by the decision trees in Figs. $1 \mathrm{a}$ and $\mathrm{b} .^{4}$

In the first case (denoted " $S$ then $G$ "), the firm begins by taking the specialized project. If the net cash flow is $2 H$, which occurs with probability $p q$, the firm knows for certain that it has both high general resources and high specific resources. Since $K^{G} \geqslant 2 K^{S}$, it will be optimal for the firm to expand in the multisegment business immediately. Conversely, if the net cash flow is $2 L$, which occurs with probability $(1-p)(1-q)$, the firm knows for certain that it has both low general resources and low specific resources, in which case it will be optimal to cease all operations. If the net cash flow is $H+L$, the firm knows that either its general resources or its specific resources are high. If $H+L>0(<0)$ then the firm might immediately scale up the specialized project (cease operation) or experiment further with the general project.

In the second case (denoted " $G$ then $S$ "), the firm begins by taking the general project. If the net cash flow is high, which occurs with probability $q$, then the firm will find it optimal to expand immediately in the multisegment business since it knows for sure that it has high general resources and $K^{G} \geqslant 2 K^{S}$. If the net cash flow is low, which occurs with probability $1-q$, the firm will never expand in the multisegment business but might find it optimal to experiment with the specialized project before deciding whether or not to scale up its specialized business.

The following proposition demonstrates that the first case dominates the second.

\section{Proposition 1. The firm will optimally undertake the specialized project at date 0.}

Proof. See the appendix.

The intuition for this result is as follows. If the firm undertakes the general project first, it will learn whether its general resources are high or low. If its general resources

\footnotetext{
${ }^{4}$ By assuming that $\mathrm{E}_{0}(G+S)$ is sufficiently small, we rule out the uninteresting case in which the firm would optimally choose to scale up its specialized project immediately.
} 

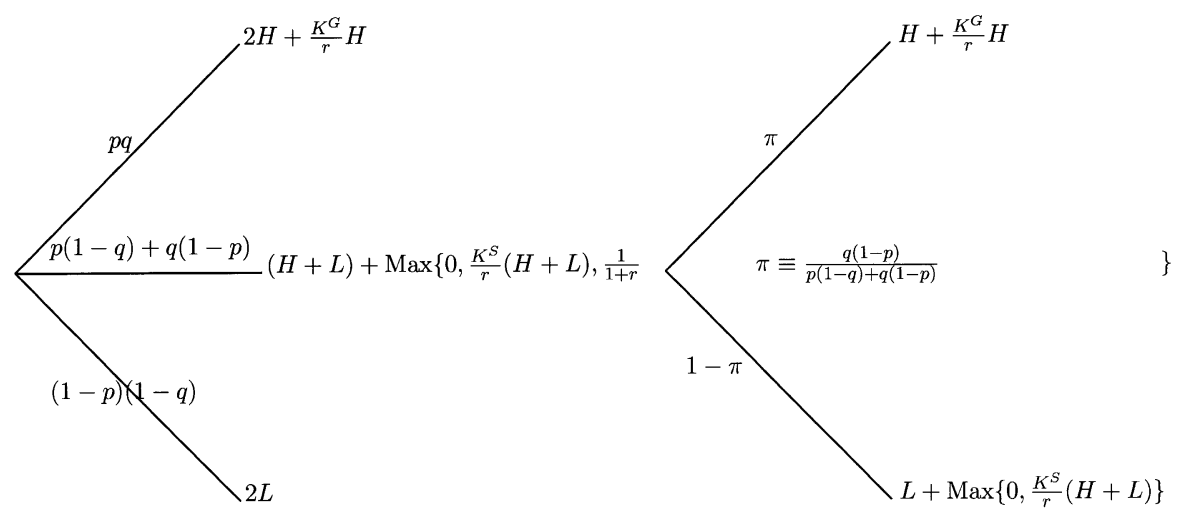

(a)

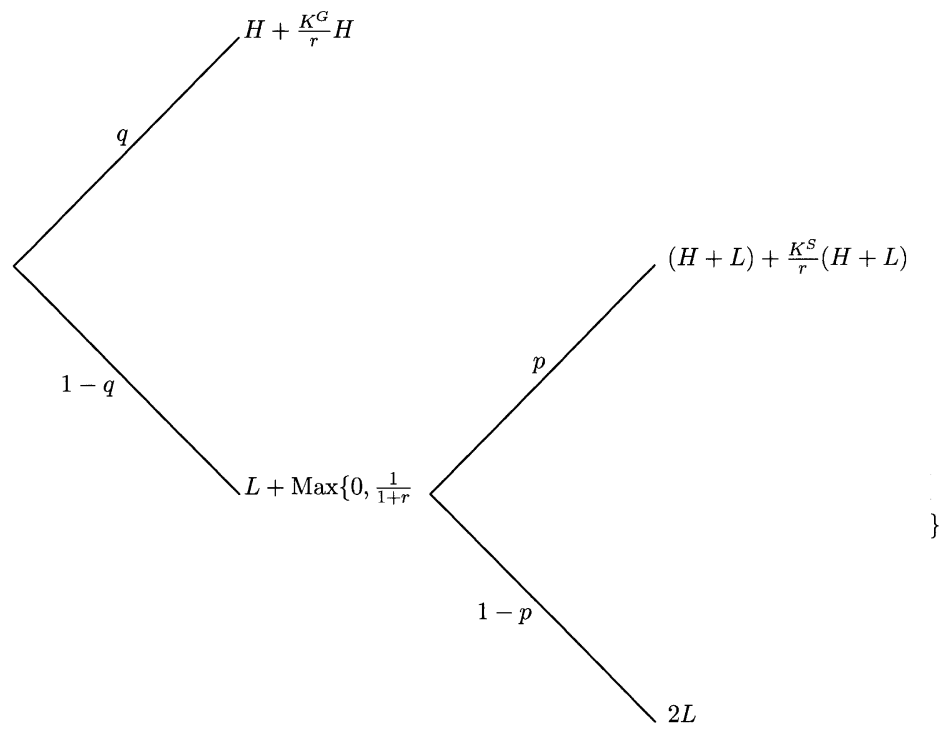

(b)

Fig. 1. (a) Specialized project first (" $S$ then $G$ "). The firm begins by taking the specialized project. If the net cash flow is $2 H$, which occurs with probability $p q$, the firm expands in the multisegment business immediately. If the net cash flow is $2 L$, which occurs with probability $(1-p)(1-q)$, the firm ceases all operations. If the net cash flow is $H+L$, the firm can immediately scale up the specialized project or cease operations or can experiment further with the general project. (b) General project first (" $G$ then $S$ "). The firm begins by taking the general project. If the net cash flow is $H$, which occurs with probability $q$, the firm expands in the multisegment business immediately. If the net cash flow is $L$, which occurs with probability $1-q$, the firm can experiment with the specialized project before deciding whether or not to scale up its specialized business. 
are high, it expands its multisegment business at date 1. If its general resources are low, it might experiment with the specialized project if the value of such an experiment, taking into account possible scaling up of the specialized project at date 2 , is positive. However, the value of such an experiment must be positive since otherwise the second case simply amounts to taking just the general project, which has a nonpositive net present value. This implies that the value of experimenting with the specialized project is positive regardless of the level of the firm's general resources. Since any advantage in learning $G$ early is not exploited in deciding whether or not to undertake the specialized project, and the net present value of taking just the general project is nonpositive, experimenting first with the specialized project dominates experimenting with the general project first.

\subsection{Implications}

The results of our model have many implications for valuation and corporate strategy. First, investment opportunities will be valued differently by firms that differ in their resource bases. This arises in part, of course, because the firm's resources directly affect the cash flows from any project. More important, however, is that when initial resources differ, what firms learn from undertaking an investment can also differ. Furthermore, the value of this information will also differ because firms have different real options.

Second, the life cycle of a firm will have the following pattern:

- The firm begins by undertaking a specialized project for which it believes it has specific resources.

- If the firm does not perform too poorly after undertaking the specialized project $\left(R^{S}=H+L\right)$, it experiments with a general project for which it might not have specific resources.

- If the firm is successful in the general project $\left(R^{G}=H>0\right)$, it expands by making a large investment in a multisegment business.

- If the firm is unsuccessful in the general project $\left(R^{G}=L<0\right)$, it either (i) ceases operations if it had also performed poorly in the specialized project $\left(R^{S}=H+L<0\right)$, or (ii) builds a larger specialized project if it was successful in it earlier $\left(R^{S}=H+L>0\right)$.

Finally, a firm might increase its investment intensity in a specialized line of business after observing a negative outcome in an unrelated line of business. This occurs when the firm has received a moderately positive signal in the past about the specialized project which could have been due to either high general resources or high specific resources. If the firm then does poorly in a general project, it will realize that it does not have high enough general resources to expand in a multisegment business. The firm's past (moderate) success in the specialized project causes the firm to expand its specialized business instead. 


\section{An extension to continuous distributions and continuous time}

In this section, we extend the model to derive a richer set of implications for the firm's optimal investment policy. We now assume that the level of resources $G$ and $S$ are drawn from a normal distribution with prior means $\left(Z_{G, 0}, Z_{S, 0}\right)$ and prior variances $\left(\sigma_{G, 0}^{2}, \sigma_{S, 0}^{2}\right)$. Let $\left(Z_{G, t}, Z_{S, t}\right)$ denote the conditional means at time $t$ and let $\left(\sigma_{G, t}^{2}, \sigma_{S, t}^{2}\right)$ denote the conditional variances of the general and the specific resources. Again, the prior and conditional means and variances are common knowledge. In general, there will be five relevant state variables in this problem: two conditional means, two conditional variances, and one conditional covariance. Solving this problem in its generality is analytically intractable. To reduce the dimensionality of the problem (and motivated by our results from the previous section), we assume that the firm has indeed begun by undertaking the specialized project and has learned perfectly its total resources, $G+S$, but it does not know the relative magnitudes of $G$ and $S$. This reduces the number of state variables from five to two (the conditional mean and variance of $G$ ). However, our model still captures the idea that firms learn about their total resources by observing the performance of their investments in a specialized business but are unable to understand perfectly the extent to which their success (failure) is due to strong (weak) general or specific resources. Our setup captures this basic idea in a simple and tractable way and allows us to focus our analysis on the interesting dynamics that follow.

The firm can then undertake a general project that generates instantaneous net cash flows of $(G+\bar{S}) \mathrm{d} t$ plus some noise. ${ }^{5}$ Specifically, we assume that the random net cash flows evolve continuously according to

$$
\mathrm{d} Y=(G+\bar{S}) \mathrm{d} t+\sigma_{\varepsilon} \mathrm{d} w
$$

where $\mathrm{d} w$ represents the standard Wiener process. For simplicity, we continue to assume that $\bar{S}=0$. This structure distinguishes two important influences on the value of undertaking the general project. First, the expected incremental cash flows depend on the level of the firm's general resources. Furthermore, the increment $\mathrm{d} Y$ conveys information about the level of the general resource $G$, which can be valuable for guiding future investment decisions. The quality of the information depends on the parameter $\sigma_{\varepsilon}$. In the limiting case when $\sigma_{\varepsilon}=0$, the firm learns $G$ perfectly in the first instant $\mathrm{d} t$. For larger values of the parameter, the firm learns more slowly, and in the limiting case where $\sigma_{\varepsilon}$ goes to infinity the firm learns nothing about $G$.

The firm continues to experiment with the general project until it either (i) ceases all operations, (ii) makes an irreversible investment in scaling up its specialized business (which generates cash flow in perpetuity with a present value at that time of $K^{S}(G+S) / r$ ), or (iii) makes an irreversible investment in building a large multisegment business (which generates cash flow in perpetuity with a present value at that time of $\left.K^{G} Z_{G, t} / r\right)$.

\footnotetext{
${ }^{5}$ We could also introduce some noise into the cash flows generated continuously while the firm is undertaking the specialized business, but this would complicate the model immensely and make it intractable.
} 
The value function for the firm's maximization problem can be written as

$$
V_{t}=\max \left[0, \mathrm{E}_{t}\left\{\mathrm{~d} Y_{t}+\frac{1}{1+r \mathrm{~d} t}\left(V_{t}+\mathrm{d} V_{t}\right)\right\}, \frac{K^{S}(G+S)}{r}, \frac{K^{G} Z_{G, t}}{r}\right] .
$$

If the maximal argument is zero, the firm ceases all operations. If the maximal argument is $K^{S}(G+S) / r$ (or $K^{G} Z_{G, t} / r$ ), the firm makes the irreversible investment in the large specialized (or multisegment) business. Otherwise, the firm continues to experiment with the general project.

Two state variables determine the value function, $Z_{G, t}$ and $\sigma_{G, t}^{2}$. For ease of notation we will drop the subscripts and define $Z \equiv Z_{G, t}$ and $\sigma^{2} \equiv \sigma_{G, t}^{2}$ so that the value function can be written as $V\left(Z, \sigma^{2}\right)$. Notice that in the stochastic process for $Y$, the firm and the investors know the diffusion parameter $\sigma_{\varepsilon}$ but do not know the drift parameter $G$; they learn about the drift parameter by observing the cash flows generated by the firm. This is a filtering problem in continuous time. Gennotte (1986) presents a simplified exposition of the filtering problem, and Jovanovic (1982) provides some results in a discrete-time formulation. The changes in the conditional expectation of $G, \mathrm{~d} Z$, and the conditional variance of $G, \mathrm{~d} \sigma^{2}$, are (from Lipster and Shiryayev, 1978) given by

$$
\begin{aligned}
\mathrm{d} Z & =\frac{\Delta}{\sigma_{\varepsilon}}\left[(G-Z) \mathrm{d} t+\sigma_{\varepsilon} \mathrm{d} w\right] \text { and } \\
\mathrm{d} \sigma^{2} & =-\Delta^{2} \mathrm{~d} t \quad \text { with } \\
\Delta & \equiv \frac{\sigma^{2}}{\sigma_{\varepsilon}} .
\end{aligned}
$$

Notice that even though $\mathrm{E}[\mathrm{d} Z]=0$ because $Z=\mathrm{E}[G]$ and $\mathrm{E}[\mathrm{d} w]=0$, the actual change in $Z$ has a drift term that equals $(G-Z)$. This is intuitive since if $Z<G$, as the firm continues to observe its cash flows, its estimate of $G$ will continue to adjust up to its true value and vice versa. Also, notice that the conditional variance of $G, \sigma^{2}$, decreases deterministically at a rate equal to $\Delta^{2}$. In the limiting case when $\sigma_{\varepsilon}^{2}=0$, $\Delta^{2} \rightarrow \infty$ and the firm learns $G$ instantly. Similarly, as $\sigma_{\varepsilon}^{2} \rightarrow \infty, \Delta^{2}=0$ and the firm learns nothing. As $\sigma^{2}$ decreases deterministically over time, it implies that $\Delta$ also decreases over time. The stochastic process for $\mathrm{d} Z$ is proportional to $\Delta$ which implies that the rate at which $Z$ approaches the true value $G$ is higher when the firm is younger. This leads to the observation, made in Jovanovic (1982), that younger firms grow faster. Moreover, it also implies that the volatility of $Z$ is also higher for younger firms. We shall see that this implies that younger firms will have a higher asset return volatility as well.

At each point in time, the firm must decide to either continue with the project, cease operations, or make a large, irreversible investment in either the specialized or the multisegment business. For any value of the state variable $\sigma^{2}$ there exist two critical values of $Z$, denoted $Z_{L}<Z_{H}$. For $Z<Z_{L}$, the estimate of the firm's general resources becomes sufficiently low that the firm decides either to cease operations (if $G+S<0$ ) or to make an irreversible investment in scaling up its specialized business. Similarly, for $Z>Z_{H}$, the estimate of the firm's general resources becomes 
sufficiently high that the firm decides to make an irreversible investment in building a larger multisegment business. For $Z \in\left(Z_{L}, Z_{H}\right)$, the firm continues to experiment with the general project, and its value function can be written as

$$
V_{t}=\mathrm{E}\left[\mathrm{d} Y_{t}+\frac{1}{1+r \mathrm{~d} t}\left(V_{t}+\mathrm{d} V_{t}\right)\right] .
$$

Using Ito's Lemma, and the fact that $\mathrm{E}[G]=Z$, we get

$$
\mathrm{d} V_{t}=\left[\frac{1}{2} \Delta^{2} V_{Z Z}\left(Z, \sigma^{2}\right)-\Delta^{2} V_{\sigma^{2}}\left(Z, \sigma^{2}\right)\right] \mathrm{d} t+\Delta V_{Z}\left(Z, \sigma^{2}\right) \mathrm{d} w
$$

which yields the following partial differential equation that the value function must satisfy:

$$
\frac{1}{2} \Delta^{2} V_{Z Z}\left(Z, \sigma^{2}\right)-\Delta^{2} V_{\sigma^{2}}\left(Z, \sigma^{2}\right)-r V\left(Z, \sigma^{2}\right)+Z=0 .
$$

The boundary conditions are provided by the following contact conditions:

$$
V\left(Z_{L}, \sigma^{2}\right)=\max \left\{0, \frac{K^{S}(G+S)}{r}\right\}
$$

and

$$
V\left(Z_{H}, \sigma^{2}\right)=\frac{K^{G} Z_{H}}{r}
$$

and the following smooth-pasting conditions:

$$
V_{Z}\left(Z_{L}, \sigma^{2}\right)=0 \quad \text { and } \quad V_{Z}\left(Z_{H}, \sigma^{2}\right)=\frac{K^{G}}{r} .
$$

This is a free boundary problem in which the critical values $Z_{L}<Z_{H}$ must be determined simultaneously as part of the solution to the partial differential equation. $^{6}$

There is no analytical solution to the partial differential equation that also satisfies the contact and the smooth-pasting conditions. However, we solve the partial differential equation numerically using a procedure that also satisfies the contact and smooth-pasting conditions. The details of this procedure are outlined in the appendix.

\subsection{Results}

\subsubsection{Calibration}

For the results presented below we choose base case parameters to reflect the cash flow distribution and valuation moments of a typical startup firm. Schwartz and Moon (2001) estimate (for several typical startup companies) that the volatility of revenues in the first two to three years after the IPO date is approximately $15 \%$. We use this estimate as a benchmark for the volatility of $G$. We assume that the noise parameter $\sigma_{\varepsilon}=0.1$. This estimate implies that the volatility of $G$ will fall from $15 \%$ to $6.5 \%$ in roughly two years, which is consistent with the half-life of revenue

\footnotetext{
${ }^{6}$ Dixit and Pindyck (1994) discuss why contact conditions as well as smooth-pasting conditions must hold for a sensible economic solution to the dynamic programming problem.
} 


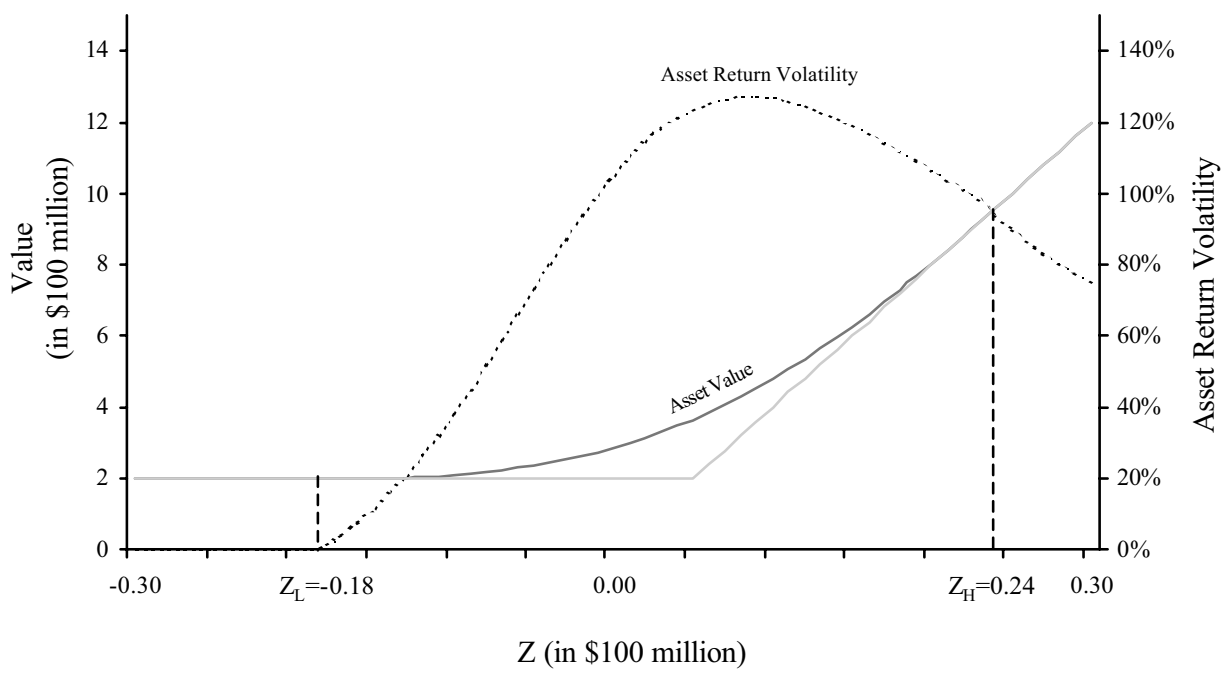

Fig. 2. Asset value and return volatility. This figure shows the asset value and asset return volatility for values of $Z$ in $[-0.3,0.3]$. Other variables are fixed at their base case values: $K^{G}=8, K^{S}=2, G+S=0.2$, $r=0.2, \sigma=0.15$, and $\sigma_{\varepsilon}=0.1$. For $Z<-0.18$, the firm optimally scales up its specialized project and achieves a value of 2 ( $\$ 200$ million). For $Z>0.24$, the firm optimally builds a multisegment business. For values of $Z$ in between, the firm optimally experiments with the general project. At $Z=0$, the value of the firm is approximately $\$ 285$ million while asset return volatility is approximately $100 \%$.

volatility decay estimated in Schwartz and Moon. We choose $r=0.2, K^{G}=8$, and $K^{S}=2$. The discount rate of $20 \%$ is a reasonable measure of the expected rate of return for a firm with a beta of approximately 2.5 as determined empirically in Schwartz and Moon for a typical technology firm soon after the IPO date. Choosing $K^{G}>K^{S}$ reflects the reasonable interpretation that there are potentially many more projects requiring general skills $G$ than specific skills $S$.

Fig. 2 depicts the value function and volatility of asset returns for various values of the conditional expectation, $Z$, of the general resources. To reflect reasonable post-IPO valuations, one unit is equal to $\$ 100$ million. For this figure we assume that $G+S=0.2$, which corresponds to $\$ 20$ million. With these parameter assumptions, we find that $Z_{L}=-0.18$ and $Z_{H}=0.24$. This means that the firm will choose to expand immediately in the specialized business (which has a present value of $\$ 200$ million) if the expected net cash flows from the general project are below $-\$ 18$ million. Conversely, the firm will choose to expand immediately in the multisegment business if the expected net cash flows from the general project are above \$24 million (which yields a present value of at least $\$ 960$ million). For expected net cash flows between $-\$ 18$ million and $\$ 24$ million, the firm continues to experiment. We find that if $Z=0$ the value of the firm is $\$ 285$ million, which is a reasonable post-IPO valuation. We also estimate the volatility of asset returns for all values of $Z$ and find that if $Z=0$, the volatility of asset returns is roughly $100 \%$. For $-0.05<Z<0.05$, volatility estimates range from roughly $75 \%$ to $125 \%$. These estimates are consistent with the $98 \%$ estimate for asset return volatility from the second round of financing 
for typical startups found in Cochrane (2001). Moreover, they are consistent with the $91 \%$ implied volatility estimate for a typical technology firm soon after the IPO date found in Schwartz and Moon (2001). In sum, our parameter choices generate reasonable cash flow dynamics and asset return moments.

\subsubsection{The effect of resource uncertainty}

In Fig. 3, we demonstrate the value of the firm and the asset return volatility as a function of $Z$ for several choices of $\sigma^{2}$. For fixed $Z$, the value of the firm is increasing in $\sigma^{2}$ because although the present value of expected future cash flows is the same, the present value of the investment option is higher. We also see that the critical value $Z_{L}$ is decreasing in $\sigma^{2}$ and $Z_{H}$ is increasing in $\sigma^{2}$. Thus, the region $\left(Z_{L}, Z_{H}\right)$ in which the firm continues to experiment shrinks as $\sigma^{2}$ falls (deterministically) over time. The logic of this result is that when $\sigma^{2}$ is high, the firm learns a lot by continuing to experiment and optimally waits to make the irreversible investment in the multisegment business unless the conditional mean of $G$ is sufficiently large. Similarly, it waits to make the irreversible investment in the specialized business (or cease operations if $G+S<0$ ) unless the conditional mean of $G$ is sufficiently small. For example, under our base case parameterization, the resource volatility falls from $15 \%$ to $8.3 \%$ in one year. At this time, the continuation region shrinks from $(-0.18,0.24)$ to $(-0.03,0.12)$. If the conditional mean $Z$ stays at zero, the value of the firm falls from $\$ 285$ million to $\$ 204$ million. The fall in value reflects a reduction in the value of the option to expand from $\$ 85$ million to $\$ 4$ million.

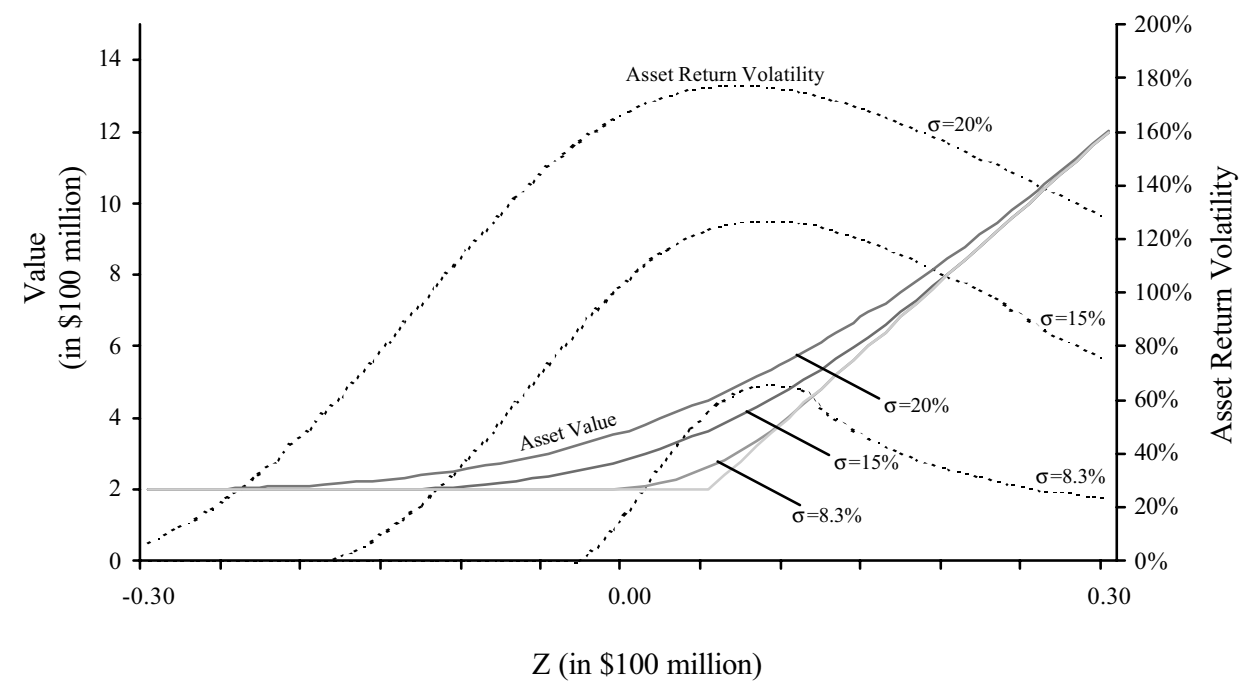

Fig. 3. Asset value, return volatility, and resource uncertainty. Asset value and asset return volatility for $Z$ in $[-0.3,0.3]$ are plotted for three different values of the resource uncertainty, $\sigma$. Other variables are fixed at their base case values: $K^{G}=8, K^{S}=2, G+S=0.2, r=0.2$, and $\sigma_{\varepsilon}=0.1$. For fixed $Z$, asset values and asset return volatility are increasing in resource uncertainty. Moreover, the region in which the firm continues to experiment with the general project is increasing in resource uncertainty. 
The asset return volatility is given by $\Delta V_{Z}\left(Z, \sigma^{2}\right) / V\left(Z, \sigma^{2}\right)$ and since $\Delta=\sigma^{2} / \sigma_{\varepsilon}$, the first-order effect is for asset return volatility to fall deterministically with $\sigma^{2}$, as seen in Fig. 3.

\subsubsection{The effect of new information and information quality}

The shape of the value function in Fig. 3 is of interest because the value of the firm $V$ is convex in $Z$, which means that if the level of $Z$ is high then positive news about $Z$ is weighted more heavily than negative news. ${ }^{7}$

In Fig. 4, we see that the value of the firm increases when $\sigma_{\varepsilon}^{2}$ decreases. This result can appear surprising because traditional real option models predict that the value function generally increases with volatility (see Dixit and Pindyck, 1994; Trigeorgis, 1996). This result demonstrates that the nature of volatility is critical for such an intuition. In our model, we get the opposite result for the parameter $\sigma_{\varepsilon}^{2}$ because for small values of $\sigma_{\varepsilon}^{2}$, the firm learns more quickly about its resources, allowing it to follow a superior investment policy in the future. We also see that $Z_{L}\left(Z_{H}\right)$ is increasing (decreasing) in $\sigma_{\varepsilon}^{2}$, so that the region $\left(Z_{L}, Z_{H}\right)$ in which the firm continues to experiment expands as $\sigma_{\varepsilon}^{2}$ decreases. This is because low $\sigma_{\varepsilon}^{2}$ means that the firm will learn more by observing the instantaneous cash flows from continuing, and thus it is willing to accept larger instantaneous losses to observe the cash flow signal. Similarly, it will delay exercising the option to make the large irreversible investment because the value of waiting is larger. For example, under our base case parameterization, if the noise volatility is $5 \%$ instead of $10 \%$, the continuation region expands from $(-0.18,0.24)$ to $(-0.27,0.32)$. If the conditional mean $Z$ remains zero, the value of the firm increases from \$285 million to \$318 million.

\subsubsection{The effect of the magnitude of the option to expand}

In Fig. 5 we examine our model with different values for $K^{G}$. Clearly, the value of the firm is increasing in $K^{G}$ because we are increasing the magnitude of a valuable option. We also see that $Z_{L}$ is decreasing in $K^{G}$, which means the firm is willing to accept larger short-term losses to learn about its general capabilities. On the other hand, because $Z_{H}$ is also decreasing in $K^{G}$, the firm will choose not to wait too long in deciding to expand its multisegment business because the incentive to expand is greater when $K^{G}$ is greater. For example, under our base case parameterization, if $K^{G}$ is 12 instead of 8 , the continuation region changes from $(-0.18,0.24)$ to $(-0.22,0.23)$. For the same conditional mean $Z=0$, the value of the firm increases from \$285 million to \$372 million.

\subsubsection{The effect of initial performance and the option to scale up the specialized business}

In Fig. 6 we examine how the observed cash flow from the specialized investment, $G+S$, affects optimal decisions and values. Note that the effect of increasing $G+S$ is qualitatively similar to increasing $K^{S}$ when $G+S>0$. First, we see that the value

\footnotetext{
${ }^{7} V$ must be convex in $Z$ because, for fixed $Z$, the value of the firm is decreasing over time $\left(\sigma^{2}\right.$ is decreasing over time) and the value function must satisfy a no-arbitrage condition.
} 


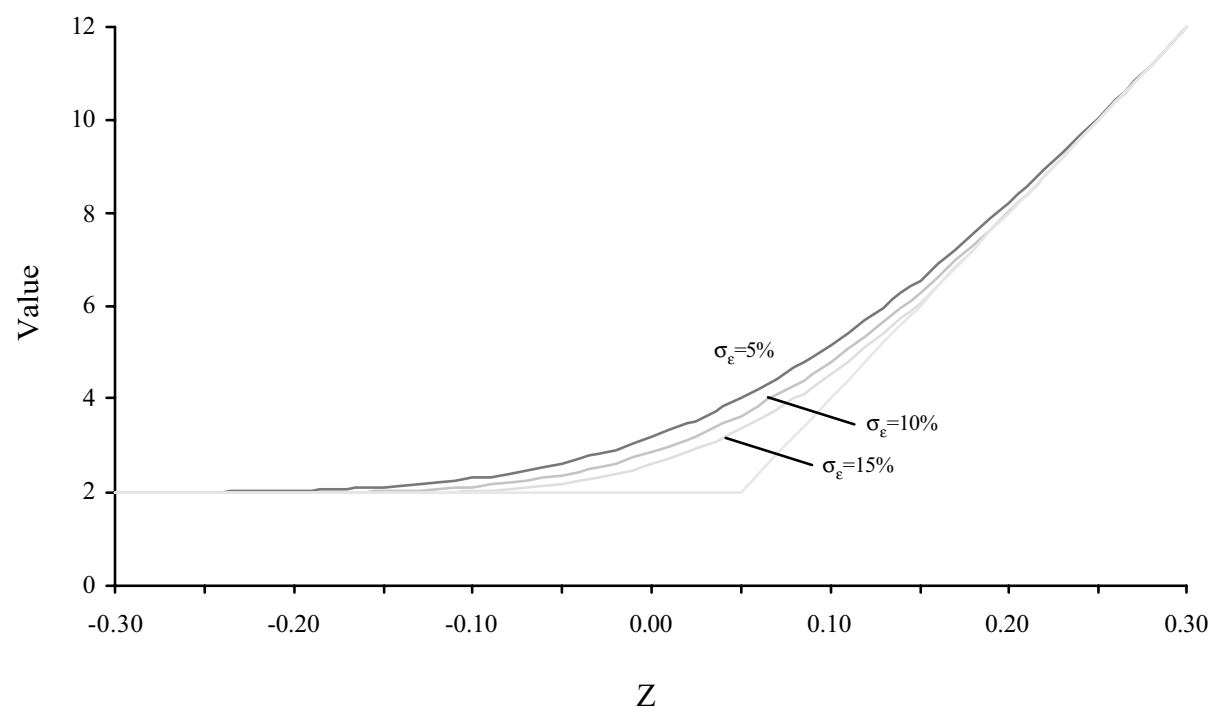

Fig. 4. Asset value and signal noise. Asset values for $Z$ in $[-0.3,0.3]$ are plotted for three different values of signal noise, $\sigma_{\varepsilon}$. Other variables are fixed at their base case values: $K^{G}=8, K^{S}=2, G+S=0.2$, $r=0.2$, and $\sigma=0.15$. Asset values are decreasing in signal noise. Moreover, the region in which the firm optimally continues to experiment with the general project decreases in $\sigma_{\varepsilon}$.

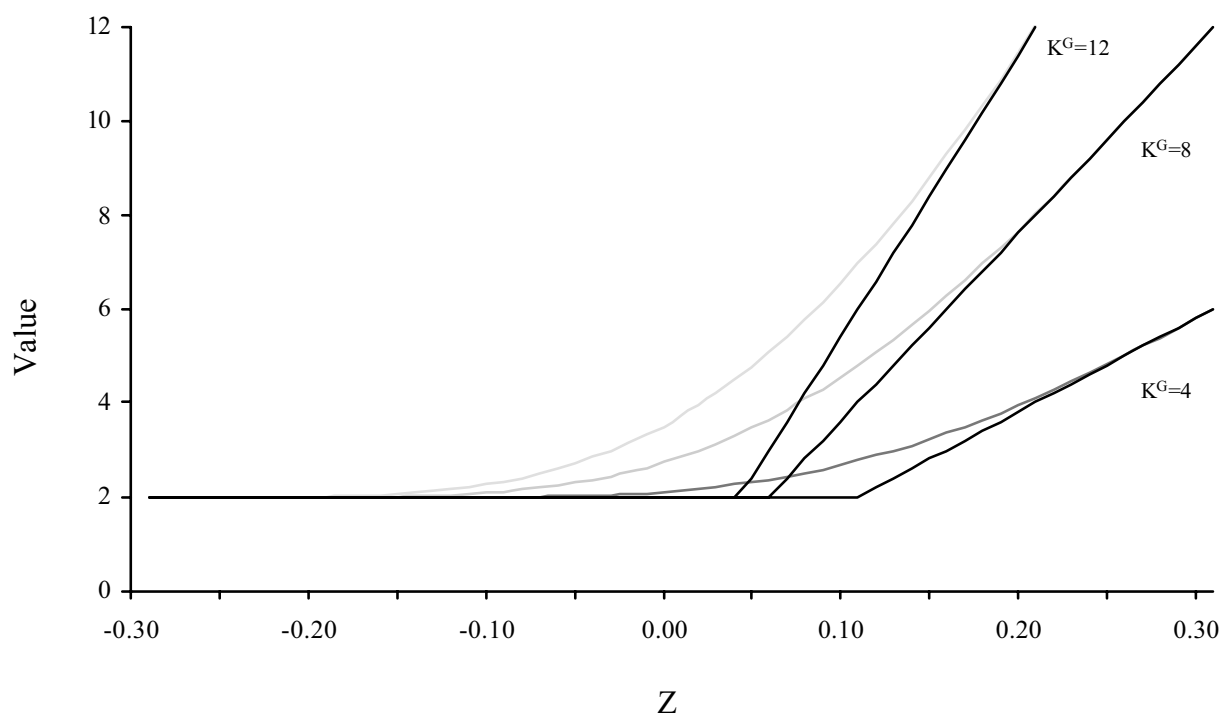

Fig. 5. Asset value and expansion scale. Asset values for $Z$ in $[-0.3,0.3]$ are plotted for three different values of the expansion scale, $K^{G}$. Other variables are fixed at their base case values: $K^{S}=2, G+S=0.2$, $r=0.2, \sigma=0.15$, and $\sigma_{\varepsilon}=0.1$. Asset values increase in the expansion scale. The region in which the firm optimally continues to experiment with the general project shifts to the left as the expansion scale increases. 


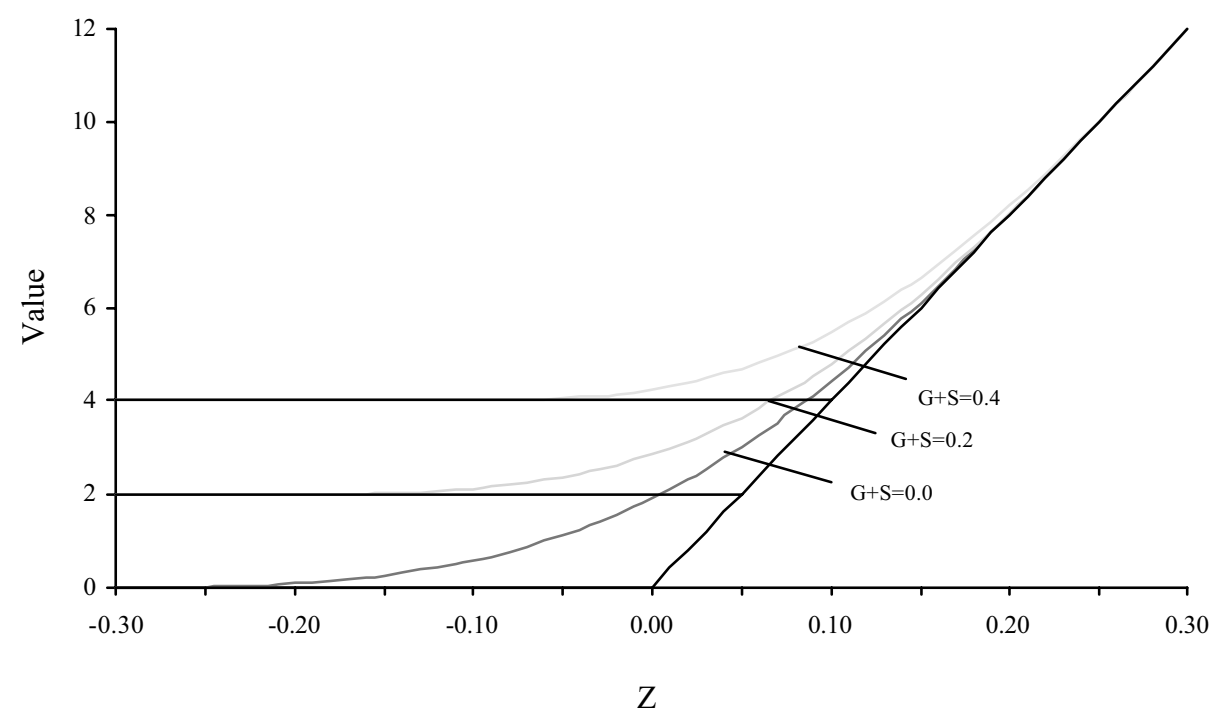

Fig. 6. Asset value and initial performance. Asset values for $Z$ in $[-0.3,0.3]$ are plotted for three different values of initial performance, $G+S$. Other variables are fixed at their base case values: $K^{G}=8, K^{S}=2$, $r=0.2, \sigma=0.15$, and $\sigma_{\varepsilon}=0.1$. Asset values increase in the initial performance. The region in which the firm optimally continues to experiment with the general project shifts to the right as the initial performance increases.

of the firm is increasing in $G+S$ for obvious reasons. Furthermore, $Z_{L}$ is increasing in $G+S$ which implies that the firm is not willing to accept large short-term losses to learn about its general resources. This is because the opportunity cost of forgoing the scaling-up of the specialized project is higher. Similarly, the firm's threshold for deciding to expand its multisegment business, $Z_{H}$, is also increasing in $G+S$. For example, under our base case parameterization, if $G+S=0.4$ instead of 0.2 , the continuation region changes from $(-0.18,0.24)$ to $(-0.09,0.27)$. For the conditional mean $Z=0$, the value of the firm increases from $\$ 285$ million to $\$ 424$ million. On the other hand, if $G+S=0$ (implying that the specialized business by itself has no value), the continuation region changes from $(-0.18,0.24)$ to $(-0.30,0.22)$. For the conditional mean $Z=0$, the value of the firm decreases from $\$ 285$ million to $\$ 191$ million, which reflects just the value of the option to expand in the multisegment business.

\subsection{Implications}

\subsubsection{Valuation}

If earnings are highly correlated from period to period (low $\sigma_{\varepsilon}^{2}$ ), the firm's value is higher. Furthermore, if it chooses to expand, its valuation at the time of expansion is higher. In Fig. 4 we observe that the value of the firm is decreasing in $\sigma_{\varepsilon}^{2}$. This occurs because lower $\sigma_{\varepsilon}^{2}$ allows the firm to learn more about its resources and make better 
investment decisions in the future. A reasonable proxy for $\sigma_{\varepsilon}^{2}$ is the degree to which earnings (cash flows) are correlated across time, with highly correlated earnings implying lower $\sigma_{\varepsilon}^{2}$. Thus, we predict that firms with highly correlated earnings will have higher values. Furthermore, when $\sigma_{\varepsilon}^{2}$ is smaller, cash flow observations from the general project have greater information value, thus the continuation region is larger, i.e., $Z_{L}$ is increasing and $Z_{H}$ is decreasing in $\sigma_{\varepsilon}^{2}$. Since the critical value, $Z_{H}$, at which the firm chooses to expand in the multisegment business is greater, a firm that chooses to expand will be more valuable at the time of expansion.

For the same expected resource levels, the value of the firm is higher when it is young. This implication also follows from our results in Fig. 3. Young firms have more uncertainty about their resources; therefore, a young firm with the same expected resources as a mature firm will have more valuable real options to expand. ${ }^{8}$ This could potentially explain what has been termed in the literature the "diversification discount": the market values of firms operating in several segments appear to be less than sum of the market values of single-segment firms operating in corresponding business segments (Lang and Stulz, 1994; Berger and Ofek, 1995). In our model, the market value of single-segment firms includes the value of real options to expand in other segments, whereas multisegment diversified firms have perhaps exhausted their options to expand. Our explanation of the measured diversification discount does not suggest any inefficiency associated with multisegment firms (Montgomery, 1994).

For the same expected resource levels, asset return volatility is higher when the firm is young. This implication also follows from our results in Fig. 3 since $\sigma^{2}$ declines over time deterministically. This implication is consistent with the empirical results in Cochrane (2001) who demonstrates that asset return volatility decreases in successive rounds of venture capital financing for startup firms.

Among the firms that expand, those that expand early have higher valuations. This implication follows directly from our results in Fig. 3. The critical point, $Z_{H}$, at which the firm optimally expands in the multisegment business is greater when there is more resource uncertainty. Thus, a firm that chooses to expand early (when resource uncertainty is high) must have learned that its general resources are very high, in which case its value is also very high. Evidence consistent with this implication appears in the literature on industry life cycle. For example, Jovanovic and MacDonald (1994b) examine the U.S. automobile tire industry and find that (i) firm market values decline over time and (ii) firms that scale up early have higher market values. Their explanation, however, is different from ours. In their analysis, firms that scale up early (invest in cost-saving technology) enjoy higher rents during the early phases of the industry life cycle; over time, technological knowhow diffuses through the industry, resulting in lower competitive prices and lower rents.

We can distinguish our theory from the alternatives by considering the following empirical predictions, which rely heavily on our real options framework.

\footnotetext{
${ }^{8}$ Jovanovic (1982) similarly shows that "younger firms have more variability in their growth rates" and "will grow faster than older firms".
} 


\subsubsection{Announcement effects}

The announcement effects of positive and negative news are asymmetric: a positive earnings surprise has a larger (positive) announcement effect than an equivalent negative earnings surprise. Furthermore, the announcement effect of a positive earnings surprise is higher if it follows other positive earnings surprises. These implications follow immediately from the result that the value function $V$ is increasing and convex in $Z$. This is a general characteristic of real options models. We now provide a sharper implication that exploits the relative magnitudes of real options to expand in a multisegment business as opposed to simply scaling up in a specialized business.

Firms whose market values are more responsive to earnings surprises (when experimenting with the general project) are more likely to expand into a multisegment business; conversely, firms whose market values are less responsive to earnings surprises are more likely to focus and scale up their specialized business. This implication follows from the result that when firms have lower $Z_{H}$ and lower $Z_{L}$, the value functions $V\left(Z, \sigma^{2}\right)$ have larger first derivatives $V_{Z}$ evaluated at a given $Z$ in the continuation region. A larger first derivative $V_{Z}$ implies that a firm's value is more sensitive to earnings news. This occurs, for example, when $K^{G}$ is high (see Fig. 5) or when $K^{S}(G+S)$ is small (see Fig. 6). A lower $Z_{H}$ implies that the firm is more likely to expand its multisegment business. Conversely, a smaller first derivative $V_{Z}$ implies that a firm's value is less sensitive to earnings news. In this case, a higher $Z_{L}$ implies that the firm is more likely to scale up its specialized project. One way to test this implication would be to construct a matched sample of specialized firms, one group with strong and the other with weak reactions to earnings announcements. We predict that firms with stronger market reactions will be more likely to expand their operations in other lines of business in the future than firms with weaker market reactions.

\section{Conclusion}

Firms learn about their resources by undertaking real investments and observing their outcomes. This has profound implications for corporate strategy and investment policies because when valuing potential investments, firms will consider both the stand-alone cash flows and the value of the information they expect to learn about the different types of resources they possess. Since firms can differ in what they know about their resources as well as in the types of real investments available, they will differentially value the information generated by the outcomes of their investments, and thus similar investment opportunities can be valued differently by firms.

We develop a model in which young firms specialize because, absent business opportunities in which they have a special skill, it might not be worthwhile for them to undertake an investment even after considering the value of information. The presence of some specialized skill, however, can make the investment worthwhile. If the firm is successful at the specialized business consistently for some period, it will learn that its total resources are high and it might have a reason to believe that its general resources are high as well. The firm now has an incentive to learn whether it is high specific resources or high general resources that are responsible for its success. 
This can induce the firm to undertake an investment in which it has no special skills but whose success depends largely on general skills. In other words, the firm has an incentive to undertake a general project so that it can learn whether its resources are principally specific or principally general. If the firm learns that it has high general skills, it can then leverage its resources into many different businesses and build a large multisegment business. If, on the other hand, the firm learns that its general skills are unusually low, it might focus and scale up its specialized business instead. Our central arguments thus allow us to predict a life cycle for firms: firms specialize when young, then experiment in a different line of business for some time, and then either expand into large multisegment firms or focus and scale up their specialized business.

We derive several empirical predictions that rely heavily on our real options framework. We clarify the intuition in many real options models that predict that higher volatility is associated with higher valuations. We show that this intuition is incorrect if higher volatility is a result of noise in observing the relevant signals about firm performance. It is the volatility of resource uncertainty that leads to higher valuations. In particular, we show that young firms that have much to learn about their resources will have higher valuations than mature firms with the same expected level of resources but less uncertainty about them. We suggest that this is a possible explanation for the "diversification" discount discussed in the literature. Furthermore, young firms will also have higher asset return volatility.

Our model also allows us to predict that among firms that expand, those that expand early have higher valuations. Evidence consistent with this appears in the literature on industry life cycle. In order to distinguish empirically our explanation from the alternatives suggested in the literature, we examine implications regarding stock price reactions. In our real options framework, the announcement effects of positive and negative news are asymmetric: a positive earnings surprise has a larger (positive) announcement effect than an equivalent negative earnings surprise. We further predict that firms whose market values are more responsive to earnings surprises (when they are experimenting with general projects) are more likely to expand into multisegment businesses. Conversely, firms whose market values are less responsive to earnings surprises are more likely to focus and scale up their specialized businesses.

We believe that incorporating the role of learning using a real options framework, as we have done in this paper, not only provides many useful insights but also has the potential to explain many empirically observed phenomena about corporate investment strategies and firm valuations.

\section{Appendix}

Proof of Lemma 1. The value of undertaking both the specialized and the general project at date 0 can be expressed as

$$
V_{\text {both }} \leqslant \mathrm{E}_{0} S+\mathrm{E}_{0} G+p(1-q) \max \left\{0, \frac{K^{S}}{r}(H+L)\right\}+\left[\mathrm{E}_{0} G+q \frac{K^{G}}{r} H\right]
$$


since the right-hand side expresses the value if the firm could separately observe the cash flows from each of the two projects.

The value of beginning with the specialized project at date $0, V_{S}$ then ${ }_{G}$, is

$$
\begin{aligned}
V_{S \text { then } G=}= & \mathrm{E}_{0} S+\mathrm{E}_{0} G+p q \frac{K^{G}}{r} H \\
& +\{p(1-q)+q(1-p)\} \max \left\{0, \frac{K^{S}}{r}(H+L), A\right\} \\
\geqslant & \mathrm{E}_{0} S+\mathrm{E}_{0} G+p q \frac{K^{G}}{r} H \\
& +\{p(1-q)+q(1-p)\} \max \left\{0, \frac{K^{S}}{r}(H+L)\right\},
\end{aligned}
$$

where

$$
\begin{aligned}
A & \equiv \frac{1}{1+r} \max \left\{0, \pi\left(H+\frac{K^{G}}{r} H\right)+(1-\pi)\left(L+\max \left\{0, \frac{K^{S}}{r}(H+L)\right\}\right)\right\} \\
& \geqslant 0
\end{aligned}
$$

represents the present value of the option to experiment with the general project and

$$
\pi=\frac{q(1-p)}{p(1-q)+q(1-p)}
$$

represents the conditional probability of $G=H$ after observing the cash flow from the specialized project $R^{S}=H+L$.

Therefore,

$$
V_{S} \text { then } G-V_{\text {both }} \geqslant p q \frac{K^{G}}{r} H+q(1-p) \max \left\{0, \frac{K^{S}}{r}(H+L)\right\}-\left[\mathrm{E}_{0} G+q \frac{K^{G}}{r} H\right] .
$$

The first two terms on the right-hand side above are obviously positive. The last term in the square brackets is the net present value of undertaking just the general project, with the possibility of expansion if $G=H$, which is nonpositive. Thus, it follows that $V_{S}$ then $G-V_{\text {both }}>0$.

Proof of Proposition 1. Let the value at date 0 if the firm begins with the general project be denoted $V_{G}$ then $S$. We will show that $V_{S}$ then ${ }_{G}>V_{G}$ then $S$ whenever $V_{G}$ then $S \geqslant 0$. From Fig. 1b we have

$$
V_{G \text { then } S}=\left[\mathrm{E}_{0} G+q \frac{K^{G}}{r} H\right]+\frac{1-q}{1+r} \max \left\{0, \mathrm{E}_{0} S+L+p \frac{K^{S}}{r}(H+L)\right\} .
$$

The term in the first square brackets is the present value of undertaking just the general project, with the possibility of expansion if $G=H$, which is negative. For $V_{G}$ then $S$ to be positive, the term in the second square brackets must be positive. Thus,

$$
V_{G \text { then } S}=\left[\mathrm{E}_{0} G+q \frac{K^{G}}{r} H\right]+\frac{1-q}{1+r}\left[\mathrm{E}_{0} S+L+p \frac{K^{S}}{r}(H+L)\right] .
$$


Now, notice that for $V_{G}$ then $S$ to be positive we must have

$$
\begin{aligned}
0 & <\mathrm{E}_{0} S+L+p \frac{K^{S}}{r}(H+L) \\
& =p H+(1-p) L+L+p \frac{K^{S}}{r}(H+L) \\
& =p\left(1+\frac{K^{S}}{r}\right)(H+L)+(1-p)(2 L)
\end{aligned}
$$

which implies that $(H+L)>0$ since $L<0$. From Fig. 1a we have

$$
\begin{aligned}
& V_{S \text { then } G=}=\mathrm{E}_{0} S+\mathrm{E}_{0} G+p q \frac{K^{G}}{r} H \\
&+\{p(1-q)+q(1-p)\} \max \left\{0, \frac{K^{S}}{r}(H+L), A\right\} \\
& \geqslant \mathrm{E}_{0} S+\mathrm{E}_{0} G+p q \frac{K^{G}}{r} H+\{p(1-q)+q(1-p)\} \frac{K^{S}}{r}(H+L) \\
&= q\left[\mathrm{E}_{0} S+H+p \frac{K^{G}}{r} H+(1-p) \frac{K^{S}}{r}(H+L)\right] \\
&+(1-q)\left[\mathrm{E}_{0} S+L+p \frac{K^{S}}{r}(H+L)\right] .
\end{aligned}
$$

Therefore,

$$
\begin{aligned}
V_{S} \text { then } G-V_{G} \text { then } S & \geqslant q\left[\mathrm{E}_{0} S+H+p \frac{K^{G}}{r} H+(1-p) \frac{K^{S}}{r}(H+L)\right] \\
& +\frac{r}{1+r}(1-q)\left[\mathrm{E}_{0} S+L+p \frac{K^{S}}{r}(H+L)\right] \\
& -\left[\mathrm{E}_{0} G+q \frac{K^{G}}{r} H\right] \\
& >0
\end{aligned}
$$

since the terms in the first two square brackets are positive and the term in the lastsquares bracket is negative.

\section{A.1. Numerical methodology}

We employ a variation of the implicit finite difference method to find approximate solutions to our problem. The key difficulty in applying any numerical method to our problem is that the partial differential equation only holds in the continuation region. Thus, for fixed values of $\sigma^{2}$ we must simultaneously find (i) the free boundaries, $Z_{L}\left(\sigma^{2}\right)$ and $Z_{H}\left(\sigma^{2}\right)$, satisfying the contact and smooth-pasting conditions and (ii) the values for all $Z$ in the continuation region. 
In the continuation region we know that the following relation holds:

$$
\frac{\sigma^{4}}{2 \sigma_{\varepsilon}^{2}} V_{Z Z}\left(Z, \sigma^{2}\right)-\frac{\sigma^{4}}{\sigma_{\varepsilon}^{2}} V_{\sigma^{2}}\left(Z, \sigma^{2}\right)-r V\left(Z, \sigma^{2}\right)+Z=0 .
$$

We construct a $2 n \times m$ grid representing discretized values of the states $Z$ and $\sigma^{2}$. Let $f_{i, j}$ denote the value at grid point $(i, j)$ where $-n \leqslant i \leqslant n$ and $0 \leqslant j \leqslant m$ are integers. If the stepsizes are given by $\mathrm{d} Z$ and $\mathrm{d} \sigma^{2}$ then $f_{i, j} \cong V\left(i \mathrm{~d} Z, j \mathrm{~d} \sigma^{2}\right)$.

Using finite differences we can approximate $V_{Z Z}$ and $V_{\sigma^{2}}$ by

$$
\begin{aligned}
V_{Z Z}\left(i \mathrm{~d} Z, j \mathrm{~d} \sigma^{2}\right) & \cong \frac{f_{i+1, j}-2 f_{i, j}+f_{i-1, j}}{(\mathrm{~d} Z)^{2}}, \\
V_{\sigma^{2}}\left(i \mathrm{~d} Z, j \mathrm{~d} \sigma^{2}\right) & \cong \frac{f_{i, j}-f_{i, j-1}}{\mathrm{~d} \sigma^{2}} .
\end{aligned}
$$

Substituting these expressions into our partial differential equation and using the fact that $Z=i \mathrm{~d} Z$ and $\sigma^{2}=j \mathrm{~d} \sigma^{2}$, we have

$$
f_{i, j-1}=a f_{i+1, j}+b_{j} f_{i, j}+a f_{i-1, j}+d_{i, j},
$$

where

$$
\begin{aligned}
& a=-\frac{\mathrm{d} \sigma^{2}}{2(\mathrm{~d} Z)^{2}} \\
& b_{j}=1+\frac{\mathrm{d} \sigma^{2}}{(\mathrm{~d} Z)^{2}}+\frac{r \sigma_{\varepsilon}^{2} \mathrm{~d} \sigma^{2}}{\left(j \mathrm{~d} \sigma^{2}\right)^{2}}, \\
& d_{i, j}=-\frac{i \mathrm{~d} Z \mathrm{~d} \sigma^{2} \sigma_{\varepsilon}^{2}}{\left(j \mathrm{~d} \sigma^{2}\right)^{2}} .
\end{aligned}
$$

We begin by considering the gridpoints for $j=1$. We know the boundary conditions $f_{i, 0}=\max \left\{0, K^{S}(G+S) / r\right\} \quad$ if $\quad i<0 \quad$ and $\quad f_{i, 0}=\max \left\{K^{S}(G+S) / r\right.$, $\left.K^{G} i \mathrm{~d} Z / r\right\}$ if $i \geqslant 0$. We begin by solving for $f_{i, 1}$ for all $i$ in the continuation region. We do not know, however, the critical values of $i_{L^{*}}$ and $i_{H^{*}}$ corresponding to the low and high free boundaries. To find these boundaries and the values $f_{i, j}$ simultaneously we adopt the following procedure. First, consider the values $f_{0,1}$ and $f_{1,1}$. To find these values we use the corresponding equations from (A.2). Specifically, we have

$$
\begin{aligned}
& f_{0,0}=a f_{1,1}+b_{1} f_{0,1}+a f_{-1,1}+d_{0,1}, \\
& f_{1,0}=a f_{2,1}+b_{1} f_{1,1}+a f_{0,1}+d_{1,1} .
\end{aligned}
$$

To solve for $f_{0,1}$ and $f_{1,1}$ we need to impose values for $f_{-1,1}$ and $f_{2,1}$. We will assume that the points $(-1,1)$ and $(2,1)$ are outside of the continuation region so that $f_{-1,1}=\max \left\{0, K^{S}(G+S) / r\right\}$ and $f_{2,1}=\max \left\{K^{S}(G+S) / r, 2 K^{G} \mathrm{~d} Z / r\right\}$. Notice that this assumption gives lower bounds on the true values of $f_{-1,1}$ and $f_{2,1}$ because if the points are truly in the continuation region then the true values would have to be at least as great. We have a system of two equations to determine the two unknown values, $f_{0,1}$ and $f_{1,1}$. Our next step is to check if the solution for the value $f_{1,1}>$ 
$\max \left\{K^{S}(G+S) / r, K^{G} \mathrm{~d} Z / r\right\}$. If it is then we know $f_{1,1}$ must be in the continuation region because this is a lower bound estimate of the value. We can now proceed to the adjacent point $f_{2,1}$ to determine if it is in the continuation region. We now must solve the new system:

$$
\begin{aligned}
& f_{0,0}=a f_{1,1}+b_{1} f_{0,1}+a f_{-1,1}+d_{0,1}, \\
& f_{1,0}=a f_{2,1}+b_{1} f_{1,1}+a f_{0,1}+d_{1,1}, \\
& f_{2,0}=a f_{3,1}+b_{1} f_{2,1}+a f_{1,1}+d_{2,1} .
\end{aligned}
$$

We impose the condition $f_{3,1}=\max \left\{K^{S}(G+S) / r, 3 K^{G} \mathrm{~d} Z / r\right\}$ and solve for the unknowns $f_{0,1}, f_{1,1}$, and $f_{2,1}$. If $f_{2,1}>\max \left\{K^{S}(G+S) / r, 2 K^{G} \mathrm{~d} Z / r\right\}$ then we know that the point $(2,1)$ is in the continuation region. We continue in this manner, adding one point to the system if the last point was determined to be in the continuation region and then solving the entire system simultaneously for the unknown values. When we find a point that does not exceed the boundary condition we stop moving in this direction. However, this point is not necessarily $i_{H}^{*}(j)$ because our estimated values are biased down since we have assumed that $f_{-1,1}=\max \left\{0, K^{S}(G+S) / r\right\}$ which may not be true.

The next step is to consider values to the left of $f_{0,1}$. Beginning with $f_{-1,1}$ we use the corresponding equations from (A.2) for all values $i=-1,0,1, \ldots, i^{s}$ where $i^{s}$ is the last increment $i$ that satisfied the condition $f_{i, 1}>\max \left\{K^{S}(G+S) / r, K^{G} i \mathrm{~d} Z / r\right\}$ in the iterative scheme above. This yields a system of $i^{s}+2$ equations to determine the $i^{s}+2$ unknowns $f_{-1,1}, f_{0,1}, \ldots, f_{i^{s}, 1}$. We then check the solution to see if $f_{-1,1}>$ $\max \left\{0, K^{S}(G+S) / r\right\}$. If it does, we add the point $f_{-2,1}$ to the system. We continue adding adjacent points until we find a point where $f_{i, 1}<\max \left\{0, K^{S}(G+S) / r\right\}$. We now stop looking in this direction and go back to the rightmost points. If $f_{i^{s}+1,1}>$ $\max \left\{K^{S}(G+S) / r, K^{G}\left(i^{S}+1\right) \mathrm{d} Z / r\right\}$ we continue adding adjacent points until we find a point that does not exceed the boundary condition, at which point we end our search on this side and switch to the left side to continue our search for the left boundary. We continue iterating in this way until we make no progress in either direction. This procedure simultaneously yields our estimates of $i_{L^{*}}, i_{H^{*}}$, and all of the values in between. Furthermore, it can be shown that value-matching and smooth-pasting conditions will hold arbitrarily well at both of these points if we choose the step size $\mathrm{d} Z$ small enough. We now have solved our problem for $j=1$. We repeat the procedure for the case $j=2$ and work backward through the grid for all $j$.

\section{References}

Arrow, K.J., 1962. The economic implications of learning-by-doing. Review of Economic Studies 29, $155-173$.

Berger, P., Ofek, E., 1995. Diversification's effect on firm value. Journal of Financial Economics 37, 39-65. Berk, J., Green, R., Naik, V., 1999. Valuation and return dynamics of new ventures. Unpublished working paper, University of California, Berkeley. 
Chandler Jr., A.D., 1990. Scale and Scope: The Dynamics of Industrial Capitalism. Harvard University Press, Cambridge.

Cochrane, J.H., 2001. The risk and return of venture capital. Unpublished working paper, University of Chicago.

Dixit, A., Pindyck, R., 1994. Investment under Uncertainty. Princeton University Press, Princeton.

Easley, D., Keifer, N.M., 1988. Controlling a stochastic process with unknown parameters. Econometrica $52,1045-1064$.

Gennotte, G., 1986. Optimal portfolio choice under incomplete information. Journal of Finance 41, 733-746.

Grossman, S., Kihlstrom, R., Mirman, L., 1977. A Bayesian approach to the production of information and learning-by-doing. Review of Economic Studies 44, 533-548.

Hopenhayn, H.A., 1992. Entry, exit, and firm dynamics in long run equilibrium. Econometrica 60, $1127-1150$.

Jovanovic, B., 1982. Selection and the evolution of industry. Econometrica 50, 649-670.

Jovanovic, B., MacDonald, G.M., 1994a. Competitive diffusion. Journal of Political Economy 102, 24-52.

Jovanovic, B., MacDonald, G.M., 1994b. The life cycle of a competitive industry. Journal of Political Economy 102, 322-347.

Lang, L., Stulz, R., 1994. Tobin's $q$, corporate diversification, and firm performance. Journal of Political Economy 102, 1248-1280.

Lipster, R.S., Shiryayev, A.N., 1978. Statistics of Random Processes. Springer, New York.

Matsusaka, J.G., 1998. Corporate diversification, value maximization, and organizational capabilities. Unpublished working paper, University of Southern California, Los Angeles.

Mitchell, M.F., 2000. The scope and organization of production: firm dynamics over the learning curve. RAND Journal of Economics 31, 180-205.

Montgomery, C.A., 1994. Corporate diversification. Journal of Economic Perspectives 8, 163-178.

Montgomery, C. A., Hariharan, S., 1991. Diversified expansion in large established firms. Journal of Economic Behavior and Organization, 71-89.

Montgomery, C.A., Wernerfelt, B., 1988. Diversification, Ricardian rents and Tobin's $q$. RAND Journal of Economics 19, 623-632.

Mueller, D.C., 1972. A life cycle theory of the firm. Journal of Industrial Economics 20, 199-219.

Penrose, E.T., 1959. The Theory of the Growth of the Firm. Basil Blackwell, Oxford.

Prescott, E., 1972. The multi-period control problem under uncertainty. Econometrica 40, 1043-1058.

Rob, R., 1991. Learning and capacity expansion under demand uncertainty. Review of Economic Studies $58,655-675$.

Ryan, R., Lippman, S., 2000. Optimal exit from a risky project with noisy returns. Unpublished working paper, University of California, Los Angeles.

Schwartz, E., Moon, M., 2001. Rational pricing of internet companies revisited. Unpublished working paper, University of California, Los Angeles.

Trigeorgis, L., 1996. Real Options - Managerial Flexibility and Strategy in Resource Allocation. MIT Press, Cambridge.

Wernerfelt, B., 1984. A resource-based view of the firm. Strategic Management Journal 5, 171-180.

Zeira, J., 1987. Investment as a process of search. Journal of Political Economy 95, 204-210. 